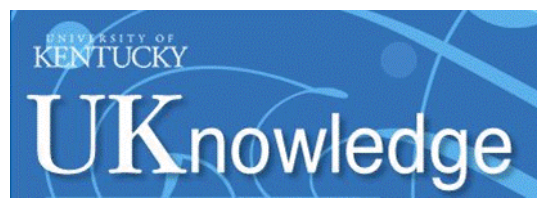

University of Kentucky

UKnowledge

\title{
Compulsive Buying and Quality of Life: An Estimate of the Monetary Cost of Compulsive Buying Among Adults in Early Midlife
}

\author{
Chenshu Zhang \\ New York University \\ Judith S. Brook \\ New York University \\ Carl G. Leukefeld \\ University of Kentucky, cleukef@uky.edu \\ Mario De La Rosa \\ Florida International University \\ David W. Brook \\ New York University
}

Follow this and additional works at: https://uknowledge.uky.edu/behavsci_facpub

Part of the Behavior and Behavior Mechanisms Commons

Right click to open a feedback form in a new tab to let us know how this document benefits you.

\section{Repository Citation}

Zhang, Chenshu; Brook, Judith S.; Leukefeld, Carl G.; De La Rosa, Mario; and Brook, David W., "Compulsive Buying and Quality of Life: An Estimate of the Monetary Cost of Compulsive Buying Among Adults in Early Midlife" (2017). Behavioral Science Faculty Publications. 45.

https://uknowledge.uky.edu/behavsci_facpub/45

This Article is brought to you for free and open access by the Behavioral Science at UKnowledge. It has been accepted for inclusion in Behavioral Science Faculty Publications by an authorized administrator of UKnowledge. For more information, please contact UKnowledge@lsv.uky.edu. 


\title{
Compulsive Buying and Quality of Life: An Estimate of the Monetary Cost of Compulsive Buying Among Adults in Early Midlife
}

\author{
Digital Object Identifier (DOI) \\ https://doi.org/10.1016/j.psychres.2017.03.007 \\ Notes/Citation Information \\ Published in Psychiatry Research, v. 252, p. 208-214. \\ (C) 2017 Elsevier B.V. All rights reserved.
}

This manuscript version is made available under the CC-BY-NC-ND 4.0 license https://creativecommons.org/licenses/by-nc-nd/4.0/.

The document available for download is the author's post-peer-review final draft of the article. 


\title{
Compulsive Buying and Quality of Life: An Estimate of the Monetary Cost of Compulsive Buying among Adults in Early Midlife
}

\author{
Chenshu Zhang ${ }^{\mathrm{a}}$, Judith S. Brook ${ }^{\mathrm{a}}$, Carl G. Leukefeld ${ }^{\mathrm{b}}$, Mario De La Rosa ${ }^{\mathrm{c}}$, and David W. \\ Brook $^{a}$ \\ aDepartment of Psychiatry, New York University School of Medicine, New York, NY 10016, USA \\ ${ }^{b}$ Department of Behavioral Sciences, University of Kentucky, Lexington, KY 40506-9983, USA \\ 'Robert Stempel College of Public Health \& Social Work, Florida International University, Miami, \\ FL 33199, USA
}

\begin{abstract}
The aims of this study were to examine the associations between compulsive buying and quality of life and to estimate the monetary cost of compulsive buying for a cohort of men and women at mean age 43. Participants came from a community-based random sample of residents in two New York counties $(\mathrm{N}=548)$. The participants were followed from adolescence to early midlife. The mean age of participants at the most recent interview was 43.0 ( $\mathrm{SD}=2.8$ ). Fifty five percent of the participants were females. Over $90 \%$ of the participants were white. Linear regression analyses showed that compulsive buying was significantly associated with quality of life, despite controlling for relevant demographic and psychosocial factors. The estimated monetary cost of compulsive buying for this cohort was significant. The fact that the monetary cost of CB is not trivial suggests that individuals are both consciously and unconsciously plagued by their $\mathrm{CB}$. The findings are important for interventionists and clinicians for cost-effective intervention and treatment programs.
\end{abstract}

\section{Keywords}

monetary cost of compulsive buying; quality of life; household income; longitudinal studies

\section{Introduction}

Compulsive buying (CB), which has been reported worldwide (e.g., Horváth et al., 2013; Koran et al., 2006), is defined as a chronic, excessive, and repetitive purchasing behavior that may be a primary response to negative events or feelings or uncontrolled urges. Koran et al. (2006) reported $5.5 \%$ of men and $6.0 \%$ of women met the criteria for CB disorder in the

Correspondence should be sent to Dr. Judith S. Brook, Department of Psychiatry, New York University School of Medicine, 215 Lexington Ave., $15^{\text {th }}$ Floor, New York, NY 10016, USA. Phone (212) 263-4662; Fax (212) 263-4660; judith.brook@ nyumc.org. Conflict of Interest

The authors report no conflict of interest. 
U.S. CB has been widely viewed as a behavioral addiction (Kellett and Bolton, 2009; Lawrence et al., 2014), with features similar to gambling disorder and internet addiction (Grant et al., 2010; Holden, 2001).

One common view is that individuals with internal distress, such as depressive mood, anxiety, or low self-esteem, depend on their CB to relieve themselves temporarily from their stressful states (Lejoyeux et al., 1996; Vogt et al., 2014). Nevertheless, instead of improving quality of life, in the long run, CB induce more negative consequences, such as the accumulation of large debts, difficulty in paying debts, financial legal consequences, and criminal legal problems (d'Astous 1990; Joireman et al., 2010; Park and Burns, 2005; Ridgway et al., 2008; Roberts, 1998). It also may result in psychological symptoms/ psychiatric disorders (e.g., emotional distress, depression) (Black, 2012; O'Guinn and Faber, 1989) and interpersonal conflict and marital conflict (Lejoyeux and Weinstein, 2010). The negative association between CB and overall quality of life is also documented (Manolis and Roberts, 2012; Otero-López et al., 2011).

Early midlife (mid forties) is a unique developmental period when the consequences of many mental health problems, including CB, become manifest. However, the extent to which an individual's CB influences his or her overall quality of life is not clear. This study intends to address this research gap. In addition, the adverse consequences of $\mathrm{CB}$ also raise the question of the monetary cost of $\mathrm{CB}$. This information is important for interventionists and clinicians for cost-effective intervention and treatment programs. In this study, we used a relatively novel approach, which is referred to as the "life satisfaction approach" (LSA) (Frey et al., 2010; Welsch and Kühling, 2009). This approach has been used to give monetary value to environmental conditions (Frey et al., 2010; Welsch and Kühling, 2009), to evaluate the trade-off between inflation and unemployment (Di Tella et al., 2001), and how much would people spend on specific health conditions (Groot and van den Brink, 2006). To our knowledge, the present study is the first study that applies this approach to the study of CB. Research has generally found that income is positively related to aspects of quality of life (e.g., Blanchflower and Oswald, 2004; Shields and Price, 2005). Using LSA, we examine the relative relationships between income and quality of life and between CB and quality of life. These relative relationships are then used to quantify the monetary cost of $\mathrm{CB}$, i.e., the amount of income needed to make someone with $\mathrm{CB}$ as well off as someone without CB. The advantage of the life satisfaction approach is that an individual is not required to perform the unfamiliar task of assessing the monetary cost on CB.

One notable limitation of the measures of self-rated quality of life is heterogeneity (Groot, 2000; Shmueli, 2002). To address the problems of this heterogeneity, in the present study we included a number of psychiatric disorders/symptoms [i.e., major depressive episode (MDE), generalized anxiety disorder (GAD), impulsivity, and legal and illegal substance dependence/abuse] as control variables in the quality of life equation. These psychiatric disorders/symptoms have been shown to be related to both quality of life and CB.

Depression is a common mental disorder that presents with depressed mood, loss of interest or pleasure, decreased energy, and feelings of guilt or low self-worth. Moreover, depression often goes along with anxiety. These problems can become chronic or recurrent and lead to 
substantial impairments in an individual's physical and psychosocial functions and low quality of life (Hofmann et al., 2014; Nes et al., 2013). Depression and anxiety are also commonly present among compulsive buyers (Black, 2007; Christenson et al., 1994; Dittmar, 2004; Lejoyeux et al., 1996; Lejoyeux et al. 1997; McElroy et al., 1994). Indeed, Lejoyeux and Weinstein (2010) reviewed the literature and found that one of the most commonly associated comorbidities of CB is depression. Therefore, we controlled for depression and anxiety in the present study. Since impulsivity and lack of self-control are commonly present among compulsive buyers (Black et al., 2012; Claes et al., 2011), we also controlled for impulsivity in our study. Some studies have shown that substance use/disorder is associated with low quality of life (Swain et al., 2012) and CB (Lejoyeux et al., 2006; Mitchell et al., 2002; Roberts and Tanner, 2000). For example, Roberts and Tanner (2000) found that self-report measures of illegal drug use were significantly associated with CB among teenagers (12-19 years). Mitchell et al. (2002) found that compulsive buyers were significantly more likely to have a lifetime history of substance abuse or dependence. So we also controlled for substance abuse/dependence.

Based on findings from other researchers, we hypothesize that adult CB will be negatively associated with adult quality of life, while household income will be positively associated with adult quality of life, despite control on earlier quality of life, concurrent MDE, GAD, impulsivity, legal and illegal substance dependence/abuse, and other important demographic factors.

In sum, the aims of this study are two-fold. First, using a community sample, we examine the association between CB and quality of life at mean age 43. Second, for the first time in the literature, using regression techniques, we derive an estimated monetary cost of $\mathrm{CB}$ in this particular cohort.

\section{Methods}

\subsection{Participants and Procedure}

Data on the participants in this study came from a community-based random sample residing in one of two upstate New York counties (Albany and Saratoga) first assessed in 1983. The participants' mothers were interviewed about the participants in 1975 (T1) to assess psychosocial development among youngsters, when the mean age of the participants was 5 years. Primary sampling units were created from enumeration districts and block groups which, when taken together, comprised the entire area of the selected counties. The primary sampling units in each county were stratified by urban/rural status, the proportion of Whites, and median family income. A systematic sample of primary sampling units in each county was then drawn with probability proportional to the number of households, and probabilities equal for members of all strata. Segments of blocks were then selected with probability proportional to size (number of households), and each was surveyed in the field with a proportion of the households being selected according to the predetermined sampling ratio. Address lists were compiled in this process, and interviewers were sent to the selected addresses. Those households with at least one child between the ages of one and ten years were qualified for the study. In each qualified household, the interviewer, by use of a set of Kish Tables (Kish, 1949), randomly selected one child from those in the appropriate age 
range. The sampled families were generally representative of families in the northeast U.S. at that time. For example, there was a close match between the participants and the 1980 U.S. Census with regard to family income, maternal education, and family structure.

Follow-up interviews of the participants were conducted seven times from 1983 (T2, $\mathrm{N}=756$ ) through 2012-2013. In the present analyses, we used the data from the two most recent interviews of this longitudinal study, when the mean ages (SDs) of the participants were 36.6 (2.8) and 43.0 (2.8) in 2005-2006 (T7, N=607) and 2012-2013 (T8, N=548), respectively. Table 1 presents the detailed history of this longitudinal study. The T2 participants who did not participate in the study at $\mathrm{T} 8(\mathrm{~N}=208)$ were excluded from the analyses. There was a higher percentage of females (55\% in the sample of 548 participants vs. $40.5 \%$ in the sample of 208 participants; $\chi 2(1)=16.3$, $p$-value $<0.001)$ and greater T2 family income (8.8 $(\mathrm{SD}=2.5)$ vs. $8.4(\mathrm{SD}=2.7) ; t=2.05, p$-value $<0.05)$ among the participants. There were no associations between those included in the analysis $(\mathrm{N}=548)$ as compared with those who were excluded $(\mathrm{N}=208)$ from the analysis with respect to age $(t=$ $0.19, p$-value $=0.85$ ).

In 2005-2006, extensively trained and supervised lay interviewers administered interviews in private. Questionnaires were self-administered by the participants in 2012-2013. Written informed consent was obtained from participants in 2005-2006 and 2012-2013. The Institutional Review Board of the New York University School of Medicine authorized the use of human subjects in this research study. Earlier waves of the study were approved by the Institutional Review Boards of the Mount Sinai School of Medicine and New York Medical College. Additional information regarding the study methodology is available in prior publications (e.g., Brook et al., 1986).

\subsection{Measures}

2.2.1 Dependent Variable-To assess quality of life, at each time wave of T7 (Mean age $=37$ ) and T8 (Mean age $=43$ ), the participants responded to 11 questions scored on a fivepoint scale (completely dissatisfied (1) to completely satisfied (5); Cronbach's $a=.90$ for this cohort at both waves; adapted from the short form of the Quality of Life Enjoyment and Satisfaction Questionnaire (Q-LES-Q-SF) (Endicott et al., 1993). The validity and reliability of Q-LES-Q-SF has been demonstrated (e.g., Endicott et al., 1993). These 11 questions follow: Taking everything into consideration, during the past few years how satisfied have you been with your: (1) mood; (2) physical health; (3) work; (4) social relationships; (5) leisure time activities; (6) ability to function in daily life; (7) sexual drive, interest, and/or performance; (8) overall sense of quality of life; (9) living/housing situation; (10) financial status; and (11) family relationships. The mean of the 11 items was used in the analysis. In this study, T8 quality of life was the dependent variable. T7 quality of life was treated as a control variable.

\subsubsection{Independent Variables}

2.2.2.1 Household income before taxes: In 2012-2013 the participants reported their total household income before taxes during the past 12 months. The participants were asked to assign themselves to the following discrete income bands: (1) $\$ 1-\$ 10,000$; (2) $\$ 10,001-$ 
$\$ 15,000$; (3) $\$ 15,001-\$ 20,000$; (4) $\$ 20,001-\$ 25,000$; (5) $\$ 25,001-\$ 35,000$; (6) $\$ 35,001-$ $\$ 50,000$; (7) \$50,001-\$75,000; (8) \$75,001-\$100,000; (9) \$100,001-\$150,000; (10) $\$ 150,001-\$ 200,000 ;(11) \$ 200,001-\$ 250,000 ;(12)$ More than $\$ 250,000$. To create a continuous measure of household income, the midpoints of these intervals were used, with the exception of the open-ended top interval. The percentage of the participants in the top income interval was 4.7\%. According to the U.S. census, the 2012-2013 mean household income of $\$ 320,000$ represented the top 5 percent of the U.S. population (DeNavas-Walt and Proctor, 2015). Therefore, we assigned $\$ 320,000$ to the top household income interval.

2.2.2.2 Compulsive Buying (CB): In 2012-2013, the participants responded to 10 questions scored on a five-point scale: strongly disagree (1) to strongly agree (5) (modified from Valence et al., 1988). The Cronbach's alpha of the scale for this cohort was .91. The construct validity and internal reliability of the Valence CB scale was established in the literature (Mueller et al., 2010; Vogt et al., 2014). Among these 10 items, 5 items relate to the tendency to spend: (1) "I feel others would be horrified if they knew of my spending habits" (2) "When I have money, I cannot help but spend part or the whole of it" (3) "I am often impulsive in my buying behavior" (4) "As soon as I enter a shopping center, I have an irresistible urge to go into a shop to buy something" (5) "I have often bought a product that I did not need, while knowing I had very little money left." There are 3 items that relate to the reactive aspect/compulsion/drive or urge to spend: (1) "For me, shopping is a way of facing the stress of my daily life and of relaxing" (2) "I sometimes feel that something inside of me pushes me to go shopping" (3) "There are times when I have a strong urge to buy (clothing, electronics, etc.)." There are also two items that reflect post-purchase guilt: (1) "At times, I have felt somewhat guilty after buying a product, because it seemed unreasonable" (2) "There are some things I buy that I do not show to anybody for fear of being perceived as irrational in my buying behavior." The mean of the 10 items was computed. We also created an indicator variable of $\mathrm{CB}$, which was used as an independent variable in the regression analysis. A participant was assigned a score of 1 if he/she scored 1 standard deviation above the sample mean.

\subsubsection{Control Variables}

2.2.3.1 Impulsivity: The participants responded to questions with regards to their impulsivity (Gough, 1957). There are 6 items scored on a four-point scale: false (1) to true (4); Cronbach's alpha $=.60$; e.g., "I often act on the spur of the moment without stopping to think." The mean of the 6 items was used in the analysis.

\subsubsection{Major Depressive Episode (MDE), Generalized Anxiety Disorder (GAD), Legal and Illegal Substance Dependence/Abuse: In 2012-2013, MDE, GAD, and legal and illegal substance dependence/abuse (i.e., illegal substance dependence/abuse, alcohol dependence/abuse, and nicotine dependence) were each assessed using the respective measures of the University of Michigan Composite International Diagnostic Interview (UM- CIDI) (Kessler et al., 1994). These measures have predictive validity and test-retest reliability (Wittchen and Kessler, 1994). These adaptations were made to make our measures consistent with the diagnoses presented in the Diagnostic and Statistical Manual of Mental Disorders, 4th ed. (DSM-IV) (American Psychiatric Association, 1994).}


MDE was ascertained if participants had a change in functioning reflected by 5 or more of the following criteria during a period lasting at least two weeks in a row in the past five years: (1) consistently depressed or down most of the day, nearly every day, or (2) markedly diminished interest or pleasure in all, or almost all, activities [either (1) or (2) must be present]; (3) significant weight loss or gain when not dieting; (4) hypersomnia or insomnia nearly every day; (5) psychomotor agitation or retardation; (6) feeling tired nearly every day; (7) feeling worthlessness or inappropriate guilt; (8) problems concentrating, and (9) recurrent thoughts about death. For the indicator variable of MDE, we assigned a score of 1 to participants diagnosed with MDE. A score of 0 was then assigned to the remainder of the sample.

GAD was ascertained if participants had a period lasting six months or more in the past five years when (1) they worried excessively or were anxious about several things most days; (2) these worries were present most days; and (3) it was difficult to control the worries or the worries interfered with their ability to focus on what they were doing. In addition, there was a change in functioning reflected by 3 or more of the following criteria: (1) feeling restless; (2) feeling tense; (3) feeling tired or weak; (4) feeling irritable; and (5) having sleep problems. For the indicator variable of GAD, we assigned a score of 1 to participants diagnosed with GAD. A score of 0 was then assigned to the remainder of the sample.

Illegal substance dependence was ascertained by the presence of three or more of the following criteria for each substance (marijuana or other illicit drugs, e.g., cocaine/crack, heroin, ecstasy, and amphetamines, etc.) used during the past year: (1) use of more of the substance than usual to get the same effect or the same amount has less of an effect than before; (2) the presence of withdrawal symptoms or the use of the substance to avoid withdrawal symptoms; (3) the use of much larger amounts of the substance than intended or use for a longer period of time than intended; (4) the presence of such a strong desire or urge to use the substance that the person could not resist using it; (5) a period of a month or more in which the person spent a great deal of time using the substance or getting over its effects; (6) the person gave up activities because of use of the substance; or (7) emotional or psychological problems resulting from using the substance such as feeling uninterested in things, feeling depressed, suspicious of people, paranoid, or having strange ideas. If a participant did not meet the criteria for substance dependence, substance abuse was ascertained by the presence of at least one of the following four criteria during the past year: (1) being under the effects of the substance or suffering its after-effects while at work or school or while taking care of children; (2) being under the effects of the substance or feeling its after-effects in a situation which increased the user's chances of getting hurt-that is, when driving a car or boat, using a knife or gun or machinery, crossing against traffic, climbing, or swimming; (3) having legal problems because of the use of the substance; or (4) having problems getting along with other people because of your use of the substance.

Alcohol dependence and abuse were ascertained using the same criteria as illegal substance dependence/abuse (see above).

A diagnosis of nicotine dependence was obtained when at least three out of the following seven criteria were endorsed by the participant: (1) physical tolerance, (2) signs of 
withdrawal when the subject refrained from smoking, (3) smoking in larger amounts and/or over a longer period than intended, (4) unsuccessful attempts to cut down or control the amount of smoking, (5) a large amount of time spent smoking (e.g., chain-smoking), (6) giving up or reducing social, occupational, or recreational activities due to smoking, and (7) continuing to smoke despite knowing it has caused mental or physical health problems.

For the indicator variable of legal or illegal substance dependence/abuse, or nicotine dependence, we assigned a score of 1 to participants diagnosed with illegal substance dependence/abuse, alcohol dependence/abuse, or nicotine dependence, respectively. A score of 0 was then assigned to the remainder of the sample.

2.2.3.3 Demographic Variables: Demographic variables were: Gender $(1=$ male; female $=0)$, T8 age (in years), T8 high school educational level or greater ( $0=$ less than a high school diploma; $1=$ high school diploma or greater), T8 marital status (1=currently married; $0=$ otherwise), and $\mathrm{T} 8$ number of people living in the household.

\subsection{Analysis}

The fundamental statistical approach is to use linear regression analysis to examine income and CB as they relate to quality of life. The Mplus software (Muthén \& Muthén, 2010) was used. To account for the non-normal distribution of the model variables, we used the Mplus maximum likelihood with robust standard errors (MLR) as the estimator. The dependent variable was T8 quality of life. The independent variables were T8 CB (standardized) and household income before taxes (in $\$ 100,000$ bracket intervals). In addition to the demographic variables (i.e., gender, T8 age, T8 marital status, T8 number of people living in household, and T8 high school educational level or greater), we also included T7 quality of life measure, T8 impulsivity, T8 MDE, T8 GAD, and T8 legal and illegal substance dependence/abuse as control variables. Specifically, we assume that quality of life $\left(\mathrm{QL}_{i}\right)$ for individual $i$ is a linear function of household income (HI), CB, and other individual characteristics (X, e.g., T8 MDE):

$$
\mathrm{QL}_{i}=\beta_{00}+\beta_{10} \mathrm{HI}_{i}+\beta_{20} \mathrm{CB}_{i}+\beta_{30} \mathrm{X}_{i}+\mu_{i},
$$

where $\beta$ represents coefficients that measure the marginal impact of $\mathbf{C B}$ and $\mathbf{H I}$, and $\mathbf{X}$ on $\mathbf{Q} \mathbf{L}$, and $\mu$ is a normally distributed random error term. The parameter estimates are used to calculate the monetary cost (MC) of $\mathrm{CB}$, i.e. the amount of household income needed to make an individual with $\mathrm{CB}$ as well off as someone without $\mathrm{CB}$. An individual with $\mathrm{CB}$ $(\mathrm{CB}=1)$ has the same $\mathrm{QL}$ as someone without $\mathrm{CB}(\mathrm{CB}=0)$ if

$$
\mathrm{QL}(\mathrm{HI}, \mathrm{CB}=0, \mathrm{X})=\mathrm{QL}\left(\mathrm{HI}+\mathrm{MC}_{\mathrm{CB}}, \mathrm{CB}=1, \mathrm{X}\right) .
$$

This translates into $\mathrm{MC}_{\mathrm{CB}}=-\beta_{20} / \beta_{10}$. Since $\mathrm{CB}$ may affect quality of life indirectly through an impact on household income, following Carroll et al. (2009), we also estimated a $\mathbf{Q} \mathbf{L}$ equation that omits household income, i.e.

Psychiatry Res. Author manuscript; available in PMC 2017 June 01. 


$$
\mathrm{QL}_{i}=\beta_{01}+\beta_{21} \mathrm{CB}_{i}+\beta_{31} \mathrm{X}_{i}+\mu_{i}
$$

Thus, we calculated the total monetary cost (TMC) of $\mathrm{CB}$ as $\mathrm{TMC}_{\mathrm{CB}}=-\beta_{21} / \beta_{10}$. $\mathrm{TMC}_{\mathrm{CB}}$ consisted of the impact of $\mathrm{CB}$ on quality of life directly and indirectly through an impact on household income as well.

To estimate how much additional $\mathrm{R}^{2}$ of $\mathrm{T} 8$ quality of life $\mathrm{CB}$ explained, we conducted a series of regression analyses: in Step 1, only demographic variables were included as independent variables; in step 2, quality of life at T7 was added; in step 3, other individual variables (e.g., T8 MDE) were added; in step 4, T8 household income was added; in step 5, T8 CB was added; in step 6, two interactive terms were added to test the interactive effects between CB and gender and household income on T8 quality of life.

\section{Results}

Table 2 presents the mean $(S D)$ or percentage $(\%)$ of the dependent and independent variables used in the present study. The mean (SD) quality of life reported by the participants in 2012-2013 was 3.71 (0.77), essentially the same as the mean in 2005-2006. The Pearson correlations between CB and household income and quality of life was -.31 $(\mathrm{p}<.001)$ and $0.25(\mathrm{p}<.001)$, respectively.

Table 3 presents the results of the multivariate linear regression analyses of quality of life. As shown in Table 3, in Step 4, after T8 household income was added to the list of independent variables, which consisted of demographic variables (added in Step 1), T7 quality of life (added in Step 2), other individual variables (e.g., T8 MDE; added in Step 3) the $\mathrm{R}^{2}$ increased from 0.374 to $0.386[\mathrm{~F}(1,536)=10.48$, $\mathrm{p}<0.01]$. In step 5, after $\mathrm{T} 8 \mathrm{CB}$ was added, the $\mathrm{R}^{2}$ increased from 0.386 to $0.392[\mathrm{~F}(1,535)=5.28, \mathrm{p}<0.05]$. In step 6 , to test the interactive effects between $\mathrm{CB}$ and gender and household income on T8 quality of life, two interactive terms were added $[\mathrm{F}(2,533)=0.44, \mathrm{p}=0.64]$. Based on the results in Step 5, T8 CB was negatively associated with T8 quality of life $(\beta=-0.22 ; t=-2.5 ; p<.05)$; T8 household income was positively associated with $\mathrm{T} 8$ quality of life $(\beta=0.16 ; \mathrm{t}=3.01 ; \mathrm{p}<$. $01)$. Among the control variables, impulsivity $(\beta=-0.19 ; \mathrm{t}=-2.1 ; \mathrm{p}<.05), \operatorname{MDE}(\beta=$ $-0.53 ; \mathrm{t}=-4.56 ; \mathrm{p}<.001), \operatorname{GAD}(\beta=-0.5 ; \mathrm{t}=-3.94 ; \mathrm{p}<.001)$, legal and illegal substance dependence/abuse $(\beta=-0.23 ; \mathrm{t}=-2.52 ; \mathrm{p}<.05)$, and marital status $(\beta=-0.17 ; \mathrm{t}=-1.98$; $\mathrm{p}<.05$ ) were adversely associated with quality of life, while quality of life at mean age 37 ( $\beta$ $=0.38 ; \mathrm{t}=8.39 ; \mathrm{p}<.001$ ) was positively associated with quality of life at mean age 43 . In addition, the interactive effects (see column Step 6, Table 3) between CB and gender ( $\beta=$ $0.21, \mathrm{t}=1.14, \mathrm{p}>0.05)$ and between $\mathrm{CB}$ and household income $(\beta=0.06, \mathrm{t}=0.64, \mathrm{p}>0.05)$ on quality of life were not statistically significant.

Based on the estimates of the regression coefficients (Step 5, Table 3) for $\mathrm{CB}(\beta=-0.22)$ and household income $\left(\beta=0.16\right.$ ), we computed $\mathrm{MC}_{\mathrm{CB}}$ (monetary cost of $\mathrm{CB}$ ) as 1.38 $(0.22 / 0.16)$, i.e., the monetary cost of $\mathrm{CB}$ was about $\$ 138,000$ (household income was coded in $\$ 100,000$ brackets intervals). Using the estimates of the regression that omitted household 
income (for $\mathrm{CB}, \beta=-0.22 ; \mathrm{t}=-2.42 ; \mathrm{p}<.05 ; \mathrm{R}^{2}=0.38$ ), the estimate of total monetary cost (TMC) of CB was not significantly different from the monetary cost (MC) of CB.

\section{Discussion}

To our knowledge, this is the first longitudinal study to estimate the quality of life equation and then to calculate the monetary cost of CB among men and women at mean age 43 , while controlling for earlier quality of life, concurrent psychiatric disorders (i.e, MDE, GAD, impulsivity, and legal and illegal substance dependence and abuse), and other relevant demographic factors. In support of our hypotheses and in accord with findings of other research (e.g., Manolis and Roberts, 2012), the findings indicate that greater CB is significantly associated with lower quality of life at mean age 43 , despite controlling for the factors cited above. Using the life satisfaction approach, we computed the monetary cost of $\mathrm{CB}$, which was substantial for this cohort.

Since the effects from impulsivity, MDE, GAD, and legal and illegal substance dependence/ abuse are partialled out, the adverse association between CB and quality of life may be explained by beliefs of materialism held by compulsive buyers (Dittmar, 2005). Materialism is defined as "individual differences in people's long-term endorsement of values, goals, and associated beliefs that center on the importance of acquiring money and possessions that convey status." (Dittmar et al., 2014). According to Dittmar et al. (2014), individuals with beliefs of materialism, when exposed to messages conveying upward social comparisons, tend to devaluate their ideal lifestyle. In addition, the pursuit of materialistic values and goals may crowd out or undermine the satisfaction of psychological needs that are essential for psychological thriving. Although not listed as an addiction, CB appears to share certain characteristics common in addictive disorders. For example, CB appears to be related to a craving to purchase things, perhaps specific things (Black et al., 2012). Although further study of this characteristic would be useful, because of the characteristic of craving, some people may consider CB to be a behavioral or process addiction, similar to gambling, sexual or internet addictions, or other compulsive behaviors. As with other kinds of addictions, quality of life may be aversely affected, and depression mood and anxiety may be seen. In addition, the similarity to other addictive disorders may be noted in brain changes which occur in other behavioral addictions (e.g., Raab, et al., 2011). Among the adverse effects seen in CB and in other addictive disorders, personal and family financial difficulties may be a result (d'Astous 1990; Joireman et al., 2010; Park and Burns, 2005; Ridgway et al., 2008; Roberts, 1998), and conflictual family relationship may be seen. According to the family interactional theory (FIT, Brook et al., 1990), conflictual family relationships, in turn, are associated with a lower quality of life.

Household income has a statistically significant positive association with quality of life. However, the size of the income effect is small, which is in accord with findings in the literature (Blanchflower and Oswald, 2004). Other things unchanged, a \$100,000 increase in household income would only increase quality of life by 0.16 .

As expected, several control variables were significantly associated with quality of life. In accord with Swain et al. (2012), we found that legal and illegal substance dependence/abuse 
was adversely associated with quality of life. Consistent with other investigator's findings (e.g., Black et al., 2012; Hofmann et al., 2014; Nes et al., 2013), we found that those who had mental disorders, such as MDE, GAD, and/or impulsivity had significantly lower quality of life as compared to their counterparts.

Some limitations should be noted. First, the present study relies on self-reported measures, which may be problematic in terms of their reliability and validity. However, many of the measures are reliable and have predictive validity. Notably, studies have shown that measures of self-rated quality of life have internal consistency, validity, reliability, and have a high degree of stability over time (Endicott et al., 1993). Second, the Valence's CB scale used in their study was not developed to identify potential compulsive buyers, and therefore a cutoff value for separating potential compulsive buyers from ordinary people is not available. In addition, past CB was not assessed. Ideally, to strengthen the results, both earlier and concurrent CB should be included in the equation. The present study does not enable us to provide inferences regarding causality. For example, T8 CB could be due to low quality of life at T7 and/or T8. Future research should focus on assessing the causal ordering of CB and quality of life. Third, this study is limited because the sample was comprised of predominantly white participants. Related to this, about $50 \%$ of the participants lived in the Albany/Saratoga area at T8. It should be noted that the estimated monetary cost of CB is only applied to the population from which the sample was drawn. Therefore, the findings may not be generalizable to racial/ethnic minority groups or individuals living in other parts of the country. Fourth, despite a number of strengths, the life satisfaction approach has its own weakness. A major caveat is that the life satisfaction approach relies on the assumption of cross-individual comparability of subjective quality of life. In addition, the estimates of monetary cost are prone to bias due to unobserved heterogeneity among individuals, which may include scale of reference bias (Groot, 2000), reporting bias (Shmueli, 2002), and statedependent bias (Kerkhofs and Lindeboom, 1995). Nevertheless, the life satisfaction approach we used in this study avoids the stringent assumptions regarding the rationality of individuals and the functioning of markets that are essential for revealed preference methods. It also avoids the use of hypothetical scenarios which may involve unreliable results and strategic behavior in the stated preference case. Fifth, our measures of legal and illegal substance dependence/abuse are not consistent with DSM-V criteria (American Psychiatric Association, 2013) due to the changes from DSM-IV to DSM-V criteria. Nevertheless, our measures of MDE and GAD are consistent with the diagnoses presented in DSM-V. Sixth, in the present study, we do not have data on the status of manic episodes, which may explain an individual's CB.

In spite of these caveats, this study provides empirical evidence that CB is adversely associated with positive quality of life, despite controlling on earlier quality of life, concurrent MDE, GAD, and impulsivity. To our knowledge, this is the first study which calculated the monetary cost of CB using the "life satisfaction" approach (Welsch and Kühling, 2009). The fact that the monetary cost of CB is not trivial suggests that individuals are both consciously and unconsciously plagued by their CB. Findings can be used to inform future studies to begin to formulate possible frameworks upon which $\mathrm{CB}$ and quality of life co-occur. Future quantitative studies may improve understanding of theoretic constructs that help explain the association between CB and quality of life. 


\section{Acknowledgments}

This research was supported by NIH grants DA032603 from the National Institute on Drug Abuse, and CA094845 from the National Cancer Institute, awarded to Dr. Judith S. Brook.

\section{References}

American Psychiatric Association. Diagnostic and Statistical Manual of Mental Disorders. Fourth. Washington, D.C.: 1994.

American Psychiatric Association. Diagnostic and Statistical Manual of Mental Disorders. Fifth. Arlington, VA: 2013.

Black DW. A review of compulsive buying disorder. World Psychiatry. 2007; 6(1):14-18. http:// europepmc.org/articles/pmc1805733. [PubMed: 17342214]

Black DW, Shaw M, McCormick B, Bayless JD, Allen J. Neuropsychological performance, impulsivity, ADHD symptoms, and novelty seeking in compulsive buying disorder. Psychiatry Res. 2012; 200(2):581-587. DOI: 10.1016/2Fj.psychres.2012.06.003 [PubMed: 22766012]

Blanchflower DG, Oswald AJ. Well-being over time in Britain and the USA. J Public Econ. 2004; 88(7):1359-1386. DOI: 10.3386/w7487

Brook JS, Brook DW, Gordon AS, Whiteman M, Cohen P. The psychosocial etiology of adolescent drug use: a family interactional approach. Genet Soc Gen Psychol Monogr. 1990; 116(2):111-267. http://web.b.ebscohost.com.ezproxy.med.nyu.edu/ehost/detail/detail? sid=62b9b440-8bf0-4656-8514-c32df782a1be \%40sessionmgr106\&vid=1\&hid=101\&bdata=JnNpdGU9ZWhvc3QtbG12ZQ\&percnt;3d $\% 3 \mathrm{~d} \# \mathrm{AN}=2376323 \& \mathrm{db}=\mathrm{mnh}$. [PubMed: 2376323]

Brook JS, Whiteman M, Gordon AS, Cohen P. Dynamics of childhood and adolescent personality traits and adolescent drug use. Dev Psychol. 1986; 22(3):403-414. DOI: 10.1037/0012-1649.22.3.403

Carroll N, Frijters P, Shields MA. Quantifying the costs of drought: new evidence from life satisfaction data. J Popul Econ. 2009; 22(2):445-461. DOI: 10.1007/s00148-007-0174-3

Christenson GA, Faber RJ, de Zwann M, Raymond N, Specker S, Ekern M, Mackenzie TB, Crosby RD, Crow SJ, Eckert ED. Compulsive buying: descriptive characteristics and psychiatric comorbidity. J Clin Psychiatry. 1994; 55(1):5-11. http://psycnet.apa.org/psycinfo/1994-29953-001.

Claes L, Bijttebier P, Mitchell JE, de Zwaan M, Mueller A. The relationship between compulsive buying, eating disorder symptoms, and temperament in a sample of female students. Compr Psychiatry. 2011; 52(1):50-55. DOI: 10.1016/j.comppsych.2010.05.003 [PubMed: 21220065]

d'Astous A. An inquiry into the compulsive side of "normal" consumers. Journal of Consumer Policy. 13(1):15-31. DOI: 10.1007/BF00411867

DeNavas-Walt, C., Proctor, BD. U.S. Census Bureau, Current Population Reports Income and Poverty in the United States: 2014. U.S. Government Printing Office; Washington, DC: 2015. p. 60-252.

Di Tella R, MacCulloch RJ, Oswald AJ. Preferences over inflation and unemployment: evidence from surveys of happiness. Am Econ Rev. 2001; 91(1):335-341. DOI: 10.1257/aer.91.1.335

Dittmar, H. Understanding and diagnosing compulsive buying. In: Holman Coombs, R., editor. Handbook of Addictive Disorders: A Practical Guide to Diagnosis and Treatment. John Wiley; NJ: 2004. p. 411-450.

Dittmar H. Compulsive buying-a growing concern? An examination of gender, age, and endorsement of materialistic values as predictors. Br J Psychol. 2005; 96(Pt. 4):467-491. DOI: 10.1348/000712605X53533 [PubMed: 16248937]

Dittmar H, Bond R, Hurst M, Kasser T. The relationship between materialism and personal well-being: a meta-analysis. J Pers Soc Psych. 2014; 107(5):879-924. DOI: 10.1037/a0037409

Endicott J, Nee J, Harrison W, Blumenthal R. Quality of life enjoyment and satisfaction questionnaire: a new measure. Psychopharmacol Bull. 1993; 29(2):321-326. http://psycnet.apa.org/index.cfm? fa=search.displayRecord\&uid=1994-12048-001. [PubMed: 8290681]

Frey B, Leuchinger S, Stutzer A. The life satisfaction approach to environmental valuation. Annu Rev Resour Economics. 2010; 2(1):139-160. DOI: 10.1146/annurev.resource.012809.103926 
Gough, HG. The California Psychological Inventory. Palo Alto, CA: Consulting Psychological Press; 1957.

Grant JE, Potenza MN, Weinstein A, Gorelick DA. Introduction to behavioral addictions. Am J Drug Alcohol Abuse. 2010; 36(5):233-241. DOI: 10.3109/00952990.2010.491884 [PubMed: 20560821]

Groot W. Adaptation, scale of reference bias in self assessments of quality of life. J Health Econ 2000. 2000; 19(3):403-420. DOI: 10.1016/S0167-6296(99)00037-5

Groot W, van den Brink HM. The compensating income variation of cardiovascular disease. Health Econ. 2006; 15(10):1143-1148. DOI: 10.1002/hec.1116 [PubMed: 16615037]

Hofmann SG, Wu JQ, Boettcher H. Effect of cognitive-behavioral therapy for anxiety disorders on quality of life: a meta-analysis. J Consult Clin Psychol. 2014; 82(3):375-391. DOI: 10.1037/ a0035491 [PubMed: 24447006]

Holden C. 'Behavioral' addictions: do they exist? Science. 2001; 294(5544):980-982. DOI: 10.1126/ science.294.5544.980 [PubMed: 11691967]

Horváth C, Adigüzel F, van Herk H. Cultural aspects of compulsive buying in emerging and developed economies: a cross cultural study in compulsive buying. Organizations and Markets in Emerging Economies. 2013; 4:8-24. https://www.researchgate.net/publication/ 259569787_Cultural_Aspects_of_Compulsive_Buying_in_Emerging_and_Developed_Economies _A_Cross_Cultural_Study_in_Compulsive_Buying.

Joireman J, Kees J, Sprott D. Concern with immediate consequences magnifies the impact of compulsive buying tendencies on college students' credit card debt. J Consum Aff 2010. 2010; 44(1):155-178. DOI: 10.1111/j.1745-6606.2010.01161.x

Kellett S, Bolton JV. Compulsive buying: a cognitive-behavioural model. Clin Psychol Psychother. 2009; 16(2):83-99. DOI: 10.1002/cpp.585 [PubMed: 19229837]

Kerkhofs M, Lindeboom M. Subjective health measures and state-dependent reporting errors. Health Econ. 1995; 4:221-235. DOI: 10.1002/hec.4730040307 [PubMed: 7550772]

Kessler RC, McGonagle KA, Zhao S, Nelson CB, Hughes M, Eshleman S, Wittchen HU, Kendler KS. Lifetime and 12-month prevalence of DSM-III-R psychiatric disorders in the United States: Results from the National Comorbidity Survey. Arch Gen Psychiatry. 1994; 51(1):8-19. DOI: 10.1001/archpsyc.1994.03950010008002 [PubMed: 8279933]

Kish L. A procedure for objective respondent selection within the household. J Am Stat Assoc. 1949; 44(247):380-387. DOI: $10.2307 / 2280236$

Koran L, Faber R, Aboujaoude E, Large M, Serpe R. Estimated prevalence of compulsive buying behavior in the United States. Am J Psychiatry. 2006; 163(10):1806-1812. DOI: 10.1176/ajp. 2006.163.10.1806 [PubMed: 17012693]

Lawrence LM, Ciorciari J, Kyrios M. Cognitive processes associated with compulsive buying behaviours and related EEG coherence. Psychiatry Res Neuroimaging. 2014; 221(1):97-103. DOI: 10.1016/j.pscychresns.2013.10.005 [PubMed: 24239477]

Lejoyeux M, Adès J, Tassain V, Solomon J. Phenomenology and psychopathology of uncontrolled buying. Am J Psychiatry. 1996; 153(12):1524-1529. DOI: 10.1176/ajp.153.12.1524 [PubMed: 8942446]

Lejoyeux M, Kerner L, Thauvin I, Loi S. Study of impulse control disorders among women presenting nicotine dependence. Int J Psychiatry Clin Pract. 2006; 10(4):241-246. DOI: 10.1080/13651500600650000 [PubMed: 24941141]

Lejoyeux M, Tassain V, Solomon J, Adès J. Study of compulsive buying in depressed patients. Journal of Clinical Psychiatry. 1997; 58(4):169-173. DOI: 10.4088/JCP.v58n0406 [PubMed: 9164428]

Lejoyeux M, Weinstein A. Compulsive buying. Am J Drug Alcohol Abuse. 2010; 36(5):248-253. DOI: 10.3109/00952990.2010.493590 [PubMed: 20560822]

Manolis C, Roberts JA. Subjective well-being among adolescent consumers: the effects of materialism, compulsive buying, and time affluence. Appl Res Qual Life. 2012; 7(2):117-135. DOI: 10.1007/ s11482-011-9155-5

McElroy SL, Keck PE Jr, Pope HG Jr, Smith JM, Strakowski SM. Compulsive buying: a report of 20 cases. J Clin Psychiatry. 1994; 55(6):242-248. [PubMed: 8071278]

Psychiatry Res. Author manuscript; available in PMC 2017 June 01. 
Mitchell JE, Redlin J, Wonderlich S, Crosby R, Faber R, Miltenberger R, Smyth J, Stickney M, Gosnell B, Burgard M, Lancaster K. The relationship between compulsive buying and eating disorders. Int J Eat Disord. 2002; 32(1):107-111. DOI: 10.1002/eat.10053 [PubMed: 12183937]

Mueller A, Mitchell JE, Crosby RD, Gefeller O, Faber RJ, Martin A, Bleich S, Glaesmer H, Exner C, de Zwaan M. Estimated prevalence of compulsive buying in Germany and its association with sociodemographic characteristics and depressive symptoms. Psychiatry Res. 2010; 80(2):137-142. DOI: 10.1016/j.psychres.2009.12.001

Muthén, LK., Muthén, BO. Mplus user's guide. 6th. Los Angeles, CA: Muthén \& Muthén; 19982010. (Retrieved from http://www.statmodel.com/download/usersguide/Mplus\%20Users $\% 20$ Guide\%20v6.pdf)

Nes RB, Czajkowski NO, Røysamb E, Ørstavik RE, Tambs K, Reichborn-Kjennerud T. Major depression and life satisfaction: a population-based twin study. J Affect Disord. 2013; 144(1):5158. DOI: 10.1016/j.jad.2012.05.060 [PubMed: 23021825]

O'Guinn TC, Faber RJ. Compulsive buying: a phenomenological exploration. J Consum Res. 1989; 16(2):147-157. DOI: $10.1086 / 209204$

Otero-Ló JM, Pol EV, Bolaño CC, Mariño MJS. Materialism, life-satisfaction and addictive buying: Examining the causal relationships. Personality and Individual Differences. 2011; 50(6):772-776. DOI: $10.1016 /$ j.paid.2010.12.027

Park HJ, Burns LD. Fashion orientation, credit card use, and compulsive buying. J Consum Mark. 2005; 22(3):135-141. DOI: 10.1108/07363760510595959

Raab G, Elger CE, Neuner M, Weber B. A neurological study of compulsive buying behaviour. Journal of Consumer Policy. 2011; 34(4):401-413. DOI: 10.1007/s10603-011-9168-3

Ridgway NM, Kukar-Kinney M, Monroe KB. An expanded conceptualization and a new measure of compulsive buying. J Consum Res. 2008; 35(4):622-639. DOI: 10.1086/591108

Roberts JA. Compulsive buying among college students: an investigation of its antecedents, consequences, and implications for public policy. J Consum Aff. 1998; 32(2):295-319. DOI: 10.1111/j.1745-6606.1998.tb00411.x

Roberts JA, Tanner JF Jr. Compulsive buying and risky behavior among adolescents. Psychol Rep. 2000; 86(3 pt 1):763-770. DOI: 10.2466/pr0.2000.86.3.763 [PubMed: 10876324]

Shields MA, Price SW. Exploring the economic and social determinants of psychological well-being and perceived social support in England. J R Stat Soc Series A Stat Soc. 2005; 168(3):513-537. DOI: 10.1111/j.1467-985X.2005.00361.x

Shmueli A. Reporting heterogeneity in the measurement of health, health-related quality of life. Pharmacoeconomics. 2002; 20(6):405-412. DOI: 10.2165/00019053-200220060-00005 [PubMed: 12052099]

Swain NR, Gibb SJ, Horwood L, Fergusson DM. Alcohol and cannabis abuse/dependence symptoms and life satisfaction in young adulthood. Drug Alcohol Rev. 2012; 31(3):327-333. DOI: 10.1111/j. 1465-3362.2011.00339.x [PubMed: 21733007]

Valence G, d'Astous A, Fortier L. Compulsive buying: concept and measurement. Journal of Consumer Policy. 1988; 11(4):419-433. DOI: 10.1007/BF00411854

Vogt S, Hunger A, Türpe T, Pietrowsky R, Gerlach AL. Effects of mood induction on consumers with vs. without compulsive buying propensity: an experimental study. Psychiatry Res. 2014; 220(1-2): 342-347. DOI: 10.1016/j.psychres.2014.06.014 [PubMed: 25108590]

Welsch H, Kühling J. Using happiness data for environmental valuation: issues and applications. J Econ Surv. 2009; 23(2):385-406. DOI: 10.1111/j.1467-6419.2008.00566.x

White H. A heteroskedasticity-consistent covariance matrix estimator and a direct test for heteroskedasticity. Econometrica. 1980; 48(4):817-838. DOI: 10.2307/1912934

Wittchen, HU., Kessler, RC. Modifications of the CIDI in the National Comorbidity Survey: the development of the UM-CIDI. 1994. [Accessed July 2, 2016] Available at http:// www.hcp.med.harvard.edu/ncs/ftpdir/um-cidi.pdf 


\section{Table 1}

History of Data Collection.

\begin{tabular}{|lllll|}
\hline Time Wave & Year of Data Collection & Sample Size & Mean Age (Standard Deviation) & Male Percentage \\
Time 1 (T1) & 1975 (Childhood) & 973 & $5.0(2.8)$ & $51.1 \%$ \\
Time 2 (T2) & 1983 (Adolescence) & 756 & $14.1(2.8)$ & $49.6 \%$ \\
Time 3 (T3) & $1985-1986$ (Late adolescence) & 739 & $16.3(2.8)$ & $50 \%$ \\
Time 4 (T4) & 1992 (Emerging adulthood) & 750 & $22.3(2.8)$ & $49.6 \%$ \\
Time 5 (T5) & 1997 (Late 20s) & 749 & $27.0(2.8)$ & $50.1 \%$ \\
Time 6 (T6) & 2002 (Early 30s) & 673 & $31.9(2.8)$ & $47.4 \%$ \\
Time 7 (T7) & $2005-2006$ (Late 30s) & 607 & $36.6(2.8)$ & $45.6 \%$ \\
Time 8 (T8) & $2012-2013$ (Early midlife) & 548 & $43.0(2.8)$ & $45 \%$ \\
\hline
\end{tabular}

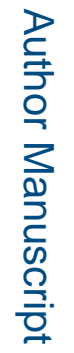

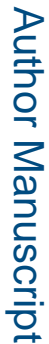

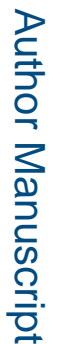




\section{Table 2}

Descriptive Statistics ( $\mathrm{N}=548)$.

\begin{tabular}{|c|c|c|}
\hline Variables & Coding & Mean (SD) or \% \\
\hline Quality of Life (2012 - 2013) & $\begin{array}{l}\text { Completely Dissatisfied (1) - Completely Satisfied } \\
\text { (5) }\end{array}$ & $3.71(0.77)$ \\
\hline Quality of Life (2005 - 2006) & $\begin{array}{l}\text { Completely Dissatisfied (1) - Completely Satisfied } \\
\text { (5) }\end{array}$ & $3.75(0.70)$ \\
\hline CB $(2012-2013)$ & No $(0)$ - Yes $(1)$ & $16.8 \%$ (Yes) \\
\hline Impulsivity (2012 - 2013) & False (1) - True (4) & $1.88(0.44)$ \\
\hline $\operatorname{MDE}(2012-2013)$ & No $(0)-$ Yes $(1)$ & $13.7 \%$ (Yes) \\
\hline GAD (2012 - 2013) & No $(0)-$ Yes $(1)$ & $11.5 \%$ (Yes) \\
\hline $\begin{array}{l}\text { Legal and illegal substance dependence/abuse (2012 - } \\
\text { 2013) }\end{array}$ & No $(0)-$ Yes $(1)$ & $20.1 \%$ (Yes) \\
\hline Household Income before Taxes (2012 - 2013) & US Dollar (\$) & $\$ 85,000^{\mathrm{a}}$ \\
\hline Gender & Female (0) - Male (1) & $45.3 \%$ (Male) \\
\hline Age $(2012-2013)$ & Years & $43.04(2.78)$ \\
\hline $\begin{array}{l}\text { High School Educational Level or Greater (2012 - } \\
\text { 2013) }\end{array}$ & $\begin{array}{l}\text { Less than a high school diploma ( } 0) \text { - High school } \\
\text { diploma or greater (1) }\end{array}$ & $\begin{array}{l}96.9 \% \text { (High School or } \\
\text { greater) }\end{array}$ \\
\hline Marital Status (2012 - 2013) & Not married (0) - Currently married (1) & $69.5 \%$ (Married) \\
\hline Number of People Living in Household & Number & $3.24(1.33)$ \\
\hline
\end{tabular}

Psychiatry Res. Author manuscript; available in PMC 2017 June 01. 


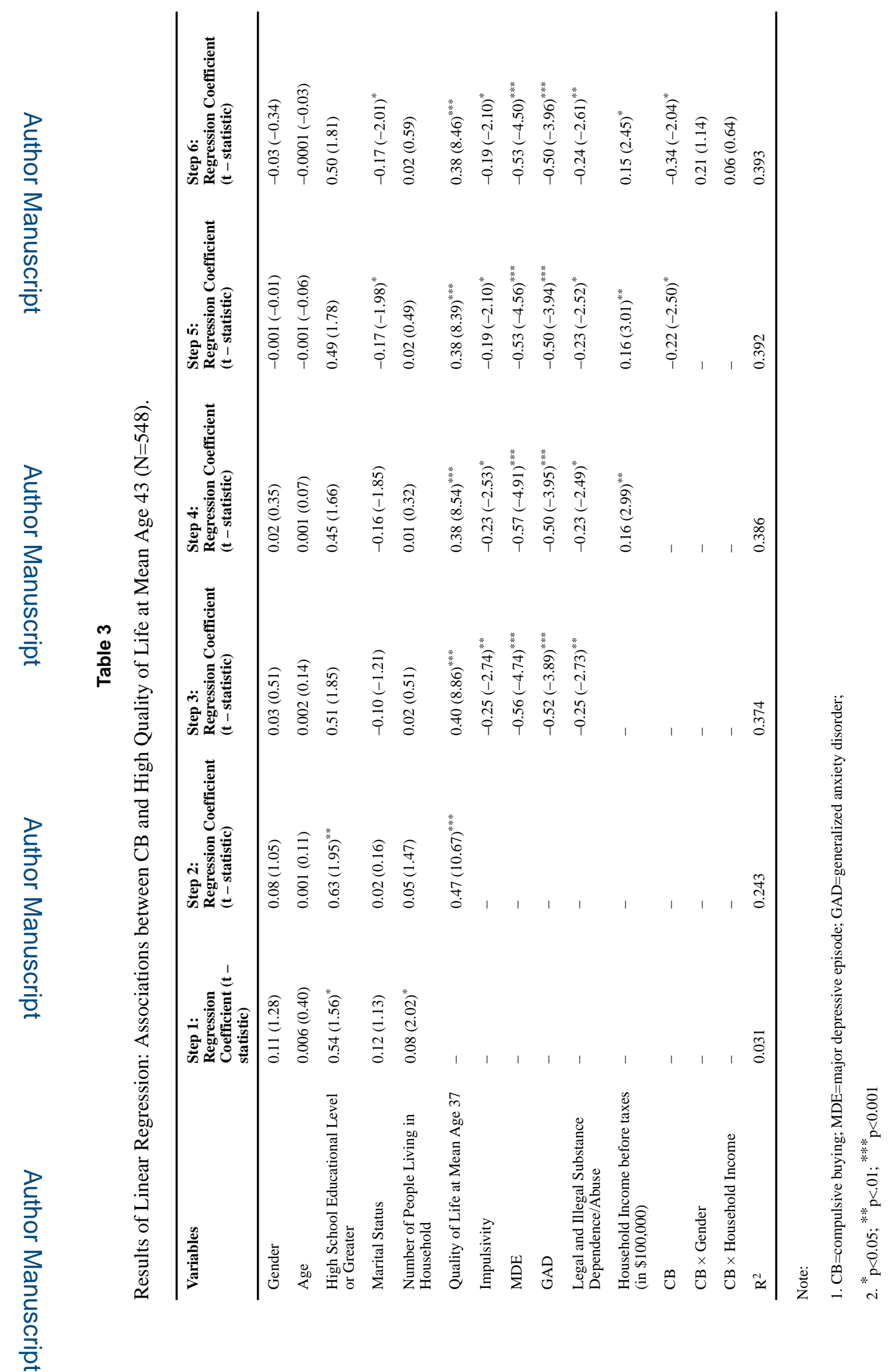

Psychiatry Res. Author manuscript; available in PMC 2017 June 01. 